\title{
On the Issue of Establishing the Stages of Coal Metamorphism for Predicting the Hazardous Properties of Coal Seams
}

\author{
M.I. Antoshchenko*, V.Y. Tarasov*t, Ye.S. Rudniev** and O.I. Zakharova*** \\ * Department of Mining, Volodymyr Dahl East Ukrainian National University, 93400, Severodonetsk, Ukraine \\ **Department of Electrical Engineering, Volodymyr Dahl East Ukrainian National University, 93400, Severodonetsk, \\ Ukraine \\ ***Department of Chemistry and Industrial Safety Measures, Volodymyr Dahl East Ukrainian National University, \\ 93400, Severodonetsk, Ukraine \\ †Corresponding author: V.Y. Tarasov; tarasov@snu.edu.ua; vatarasov81@gmail.com
}

\section{Nat. Env. \& Poll. Tech Website: www.neptjournal.com \\ Received: 05-12-2020 \\ Revised: 15-02-2021 \\ Accepted: 24-02-2021 \\ Key Words: \\ Coal \\ Metamorphism \\ Elemental composition \\ Coal seams \\ Hazardous properties}

\begin{abstract}
The characteristic stages of metamorphic transformations of mines are established according to the increase in the elemental content of carbon and changes in other components of organic matter. Stages of metamorphism transformations with an average carbon content of more than $93.6 \%$ can significantly differ in properties due to the unpredictability of the ratio between the components of organic matter. At these stages, even a minimal difference between the components can be the reason for the emergence of new properties of the coal seams. As the influence of the processes of metamorphism increases, the boundaries of the stages, determined by the percentage of carbon, narrow. The established stages of the transformation of reservoirs in terms of the individual proportion of the components in carbonization practically do not differ from the boundaries of the stages determined by the elemental composition of organic matter. It is noted that the average carbon content at the stages of seam metamorphism, determined by the yield of coke, in most cases does not coincide with the ranges of changes in the average carbon content, established by the individual content of the components or their share in carbonization. The inconsistency of the boundaries in the stages of seam metamorphism makes it unacceptable to use the coke yield as the main criterion for assessing the conversion of coal and even more so the manifestation of hazardous properties of coal seams.
\end{abstract}

\section{INTRODUCTION}

At present, it is generally accepted that some mining accidents are associated with the properties of fossil coals, which appeared as a result of geological processes and metamorphic transformations of the original organic matter. This is confirmed by the fact that the indicators of the degree of coal metamorphism are used in the modern regulatory framework of Ukraine (Antoshchenko et al. 2020) to predict gas release, gas-dynamic phenomena, endogenous fires, and the dust-generating capacity of coal seams. One of the main signs of increased metamorphic transformation of coals is an increase in the elemental content of carbon $\left(C_{0}\right)$ and a decrease in other components in the original organic matter (Thomas 2020). This, being one of the basic principles of metamorphic transformations, is not observed when predicting the hazardous properties of coal seams. Changes in the elemental composition of the initial organic matter, as the main indicator of the degree of coal metamorphism, are not considered at all in the regulatory framework (Antoshchenko et al. 2020). The methods for determining the degree of coal metamorphism in the documents under consideration were developed based on the experience of applying industrial classifications. They envisaged, first, the determination of the technological properties of coals associated with their tendency to cokeability and calorific value.

The degree of metamorphism was initially characterized by the amount of coke yield to organic matter $(K)$ and moisture content $(W)$ (Ahamed et al. 2019). These indicators, for the most part, directly characterize the consumer properties of coal. In the course of upgrading industrial classifications, approximately 30 indicators were also investigated, which, in aggregate, more clearly define the technological properties of coals than carbon $\left(C_{0}\right)$ and $W$. The modern industrial classification provides for the use of 10 indicators. The content of carbon $\left(C_{0}\right)$, as one of the main indicators of metamorphic transformations, is not considered. The maximum moisture capacity for an ashless state $\left(W_{\max }^{a f}\right)$ is limitedly used only for dividing brown coals into types. The volumetric yield of volatile substances during the thermal decomposition of coals into a dry ash-free state $\left(V_{v}^{\text {daf }}\right)$ for anthracites became 
one of the main indicators of the stages of metamorphism in industrial classifications (GOST 25543-2013 2014, GOST 6382-2007 2008) and regulatory framework (Antoshchenko et al. 2020). Essentially, thermal decomposition (GOST 6382-2007 2008) is an artificial continuation of the stages of coal transformation at temperatures $\left(900^{\circ} \mathrm{C}\right)$, significantly higher than the transformation temperature of coal (300$500^{\circ} \mathrm{C}$ ) and anthracite $\left(500-650^{\circ} \mathrm{C}\right)$ (Klymenko et al. 2019). The composition and characteristics of coals have changed over geological time, although thermal degradation products do not directly characterize this transformation. The expediency of using indicators and establishing the consumption properties of coals is confirmed by successful experience in the application of industrial classification (GOST 255432013 2014). Such a possibility of experimental verification is absent when predicting the hazardous properties of coal seams.

Recurring accidents in coal mines indicate the importance of enhancing the regulatory framework in terms of predicting the hazardous properties of coal seams. Its main disadvantage is the use of indicators that do not directly characterize the change in the elemental composition and properties of coals in the process of their metamorphic transformations. Application of indicators $V^{d a f}$ and $V_{c}^{d a f}$, without due scientific justification, is copied from industrial classifications. The latter provides for the systematization of coals according to indicators characterizing their suitability for industrial use (ASTM D388-15, 2012). The coal grades are established according to these indicators. They are commonly used to describe coal variations that are similar in genetic, basic energy, and technological properties. Industrial classifications do not provide for forecasting the manifestation of hazardous properties of coal seams during mining operations.

When determining the propensity of coal seams to manifest their dangerous properties based on genetic factors, the definition of metamorphism according to ASTM D388-15 (2012) should be taken into account. It consists of the transformation of brown coal sequentially into coal and anthracite as a result of changes in the chemical composition, structure, and physical properties of coal in the depths, mainly under the influence of elevated temperature and pressure. None of the indicators used in the regulatory framework fully comply with this definition. A direct change in the composition of the initial organic matter is not considered with an increase in metamorphism as an increase in the carbon content and a decrease in the content of other components.

\section{MATERIALS AND METHODS}

The research methodology was developed based on modern knowledge in the field of geological science, chemical analysis of coals, mining experience, and the results of statistical processing of extensive material obtained in different coal basins by many researchers. During the research, the basic principles were observed, according to which the metamorphism of fossil coals manifests itself in a change in the elemental composition of the original matter and its properties. The change in carbon content in an individual ratio with each component of organic matter should be directly characterized by classification indicators. These basic principles of metamorphism manifestation are not considered by the modern regulatory framework (Antoshchenko et al. 2020) and the current industrial classification (GOST 25543-2013. 2014).

According to the known industrial classifications, the stages of metamorphic transformations of coal seams cannot be determined for several reasons:

- The main indicators of the degree of coal metamorphism are based on the determination of the products of thermal coal decomposition. This process is an artificial continuation of the stages of the transformation of organic matter that took place in natural conditions in the past geological time periods;

- Most of the classification indicators are determined for dry ashless mass, which does not correspond to the conditions for finding coal in coal seams. In all cases, there is the presence of moisture and mineral impurities;

- Conditional coal grades are determined for their industrial use. They are artificially established according to a set of several indicators that are not directly related to the change in the elemental composition of organic matter and the manifestation of hazardous properties during mining;

- Seam moisture is not considered in the composition of organic matter, which excludes its influence on the physical state of the coal seams.

The method assumed that the main components of organic matter are carbon $\left(\mathrm{C}_{o}\right)$, hydrogen $\left(H_{o}\right)$, nitrogen $\left(N_{o}\right)$, sulfur $\left(S_{o}\right)$, oxygen $\left(O_{o}\right)$, and moisture $(W)$. Their total content at all stages of reservoir metamorphism is $97.5 \%$ and more. The average compositions of the Donetsk basin coals at different stages of seam metamorphism were taken for analysis based on the results of processing more than a thousand samples. Their results completely coincide with the average values of the elemental composition of organic matter obtained in other coal basins when processing about three thousand more data pairs (Thomas 2020, Klymenko et al. 2019, Qi 2020). The obtained results of statistical processing of such a quantity of experimental data do not raise doubts about their reliability.

The change in the content of the components of organic matter $\left(C_{o}, O_{o}, H_{o}, S_{o}, N_{o}\right)$ and moisture $(W)$ at different 
Table 1: Information on the average composition of the Donetsk basin coals at different stages of seam metamorphism.

\begin{tabular}{|lllllllllll|}
\hline Indicators, $\%$ & \multicolumn{7}{c|}{ Stages of metamorphic transformations of formations and the composition of the original organic matter } \\
\cline { 2 - 11 } & I & II & III & IV & V & VI & VII & VIII & IX & X \\
\hline$K$ & $52 \div 55$ & $55 \div 60$ & $60 \div 65$ & $65 \div 70$ & $70 \div 75$ & $75 \div 80$ & $80 \div 85$ & $85 \div 90$ & $90 \div 95$ & $95 \div 100$ \\
$\bar{K}$ & 53,5 & 57,5 & 62,5 & 67,5 & 72,5 & 77,5 & 82,5 & 87,5 & 92,5 & 97,5 \\
$V_{k}$ & $48 \div 45$ & $45 \div 40$ & $40 \div 35$ & $35 \div 30$ & $30 \div 25$ & $25 \div 20$ & $20 \div 15$ & $15 \div 10$ & $10 \div 5$ & $5 \div 0$ \\
$\bar{V}_{k}$ & 46,5 & 42,5 & 37,5 & 32,5 & 27,5 & 22,5 & 17,5 & 12,5 & 7,5 & 2,5 \\
$\bar{W}$ & 7,34 & 6,44 & 2,59 & 1,59 & 1,15 & 0,99 & 0,88 & 0,78 & 1,29 & 3,32 \\
$\bar{C}_{0}$ & 80,19 & 81,57 & 84,29 & 86,43 & 88,33 & 89,53 & 90,43 & 91,46 & 92,67 & 93,65 \\
$\bar{H}_{0}$ & 5,34 & 5,31 & 5,31 & 5,21 & 5,10 & 4,81 & 4,60 & 4,30 & 3,75 & 1,93 \\
$\bar{N}_{0}$ & 1,43 & 1,44 & 1,44 & 1,46 & 1,52 & 1,51 & 1,51 & 1,38 & 1,32 & 1,05 \\
$\bar{S}_{0}$ & 2,28 & 1,83 & 1,42 & 1,24 & 1,10 & 1,04 & 1,06 & 1,03 & 1,00 & 0,74 \\
$\bar{O}_{0}$ & 10,76 & 9,85 & 7,54 & 5,66 & 3,95 & 3,11 & 2,40 & 1,83 & 1,26 & 0,63 \\
\hline
\end{tabular}

stages of metamorphism are given in Table. 1. The initial criterion for determining the stages of metamorphism was the yield of coke to organic matter $(K)$. According to the $K$ values from 52 to $100 \%$, the conversion of seams from young coal to anthracite was evenly divided into 10 stages. The average values of the yield of coke $(\bar{K})$ at each stage were determined by the average values of the components of organic matter $\left(\bar{C}_{0}, \bar{H}_{0}, \bar{N}_{0}, \bar{S}_{0}, \bar{O}_{0}\right)$ and moisture content $(\bar{W})$ in the initial samples (Ahamed et al. 2019). Graphite $\left(C_{0} \approx 100 \%\right)$ is accepted as the final member of the coal metamorphism series. The main component of organic matter at all stages of transformation is carbon. Its minimum value for bituminous coals is about $70 \%$. Average values of carbon content at the considered 10 stages of metamorphism of formations varied in the range of $80,19 \div 93,65 \%$ (Table 1 ).

The average amount of removed fluids $\left(\bar{V}_{\kappa}\right)$, formed at different stages of formation transformation, is determined from the ratio:

$$
\bar{V}_{\kappa}=100-\bar{K}, \% \text {. }
$$

\section{RESULTS AND DISCUSSION}

With this definition $\bar{V}_{\kappa}$, its values will slightly exceed the average yield of volatile substances during the thermal decomposition of coal $\left(\bar{V}^{\text {daf }}\right)$. The $\bar{V}^{\text {daf }}$ composition considers only gaseous decomposition products, and the presence of pyrogenetic moisture and coal tar is not excluded in the removed fluids. This once again confirms the inconsistency of the indicator $\bar{V}^{\text {daf }}$ with the metamorphic transformations of seams.

As the metamorphic processes intensified (growth of $\bar{K}$ ), a one-sided increase in the carbon content occurred (Fig. 1a). Simultaneously with these processes, a decrease in the sum of the remaining components $\left(\Sigma \bar{H}_{0}, \bar{N}_{0}, \bar{S}_{0}, \bar{O}_{0}\right)$ of organic matter was observed (Fig. 1b, curve 7). The individual change in the content of organic matter components was not so unambiguous. The most intense decrease in oxygen content was observed in stages I-IV, then a more gradual decrease in stages $\mathrm{V}-\mathrm{X}$ was observed almost to zero (Fig. $1 \mathrm{~b}$, curve 2). The hydrogen content remained practically unchanged at stages I-VI and then decreased according to a nonlinear dependence (Fig. 1b, curve 3). The content of nitrogen and sulfur underwent minor changes (Fig. 1b, curves 5 and 4). In addition to the considered components of organic matter $\left(\bar{C}_{0}, \bar{H}_{0}, \bar{N}_{0}, \bar{S}_{0}, \bar{O}_{0}\right)$, it includes seam moisture $(\bar{W})$. $\bar{W}^{a}$ determination methods do not allow it to be considered together with other components $\left(\bar{C}_{0}, \bar{H}_{0}, \bar{N}_{0}, \bar{S}_{0}, \bar{O}_{0}\right)$ in a $100 \%$ composition of organic matter.

The $\bar{W}$ percentage is related to the original coal sample. The reduction in moisture content took place intensively at the initial stages (I-III) of the transformation of mine layers (Fig. 1 b, curve 6). Then its reduction was insignificant (stages IV-VII, Table 1), and an increase was observed at stages VIII-X. Such an ambiguous change in the $\bar{W}$ indica- 


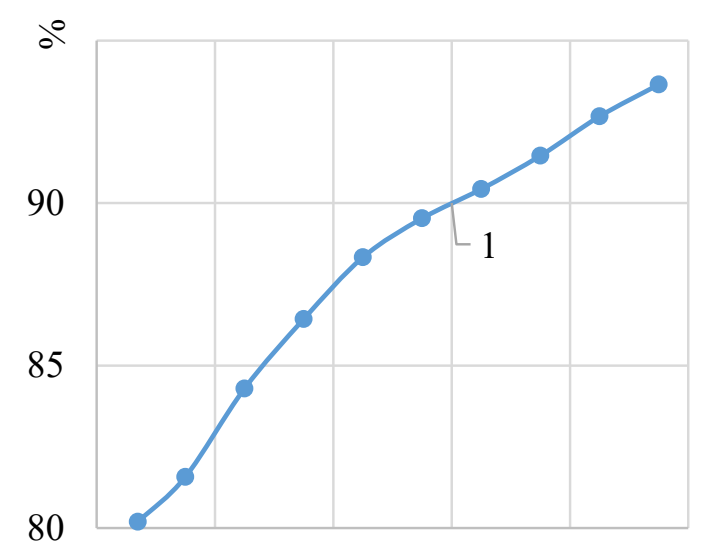

a)

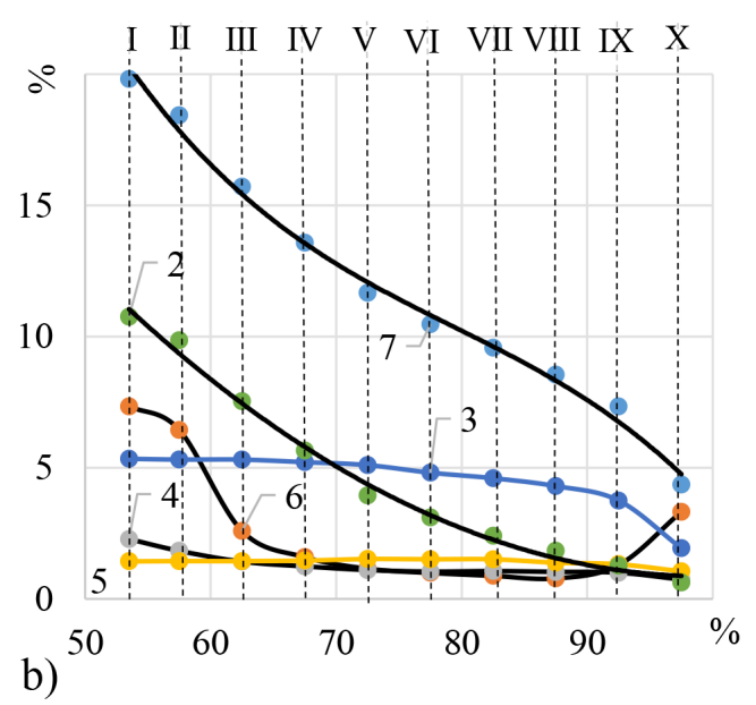

Fig. 1: Change in the average content of organic matter components from the yield of coke at different stages of metamorphic transformations of coal seams.

$1,2,3,4,5,6$ - curves of average carbon $\left(\bar{C}_{0}\right)$, oxygen $\left(\bar{O}_{0}\right)$, hydrogen $\left(\bar{H}_{0}\right)$, sulfur $\left(\bar{S}_{0}\right)$, nitrogen $\left(\bar{N}_{0}\right)$, and moisture $(W)$ content in organic matter respectively; 7 - a curve of change in the sum of components of organic matter $\left(\bar{H}_{0}, \bar{N}_{0}, \bar{S}_{0} \mathrm{H} \bar{O}_{0}\right)$; I-X - stages of metamorphic transformations of seams by coke yield.

tor certainly affects the processes of metamorphism and the manifestation of the hazardous properties of coal seams. This is evidenced by the change in the position of $\bar{W}$ the series of ranking indicators for the coke yield (Table 2). As the processes of metamorphism intensify at stages I-VI, the role of $\bar{W}$, in comparison with other components, decreases. In the ranking, $\bar{W}$ moves from the third position to the sixth. Then, at the final stages IX-X, the importance in the ranking series rises again.

Carbon content holds the indisputable top position in the evaluation ranks at all stages of reservoir transformation. The presence of other components $\left(\bar{H}_{0}, \bar{N}_{0}, \bar{S}_{0}, \bar{O}_{0}\right)$ and moisture $(\bar{W})$ in the organic matter directly depends on the $\bar{C}_{0}$ content. This gives grounds to use the change in the ratio between carbon content and other components, instead of the coke yield, for characterizing the stages of metamorphism of coal seams.

The $\bar{C}_{0}$ ratio to the sum of the hydrogen $\left(\bar{H}_{0}\right)$ and oxygen $\left(\bar{O}_{0}\right)$ content was defined as an indicator of carbonation (Sen \& Banerjee 2015). The use of only two components to determine the carbonization index $\left(C_{n}\right)$ does not give a complete picture of the effect of the nitrogen $\left(\bar{N}_{0}\right)$, sulfur $\left(\bar{S}_{0}\right)$, and moisture $(\bar{W})$ content on the increase in carbon $\left(\bar{C}_{0}\right)$ with the intensification of metamorphic processes. It is more expedient to consider all the main components of organic matter $\left(\bar{H}_{0}, \bar{N}_{0}, \bar{S}_{0}, \bar{O}_{0}\right)$ and moisture $(\bar{W})$ when determining the $C_{n}$ indicator. The carbonation index $C_{n}^{\Sigma}$ corresponding to the sum of the components of organic matter, according to Table 1, was calculated using the equation:

$$
C_{n}^{\Sigma}=\frac{\bar{C}_{0}}{\bar{H}_{0}+\bar{N}_{0}+\bar{S}_{0}+\bar{O}_{0}}
$$

Similarly, roughly, since $\bar{W}$ is not part of the $100 \%$ content of organic matter components, the carbonation index for the moisture content was calculated:

$$
C_{n}^{W}=\frac{\bar{C}_{0}}{\bar{W}}
$$

The results of determining the indicators $C_{n}^{\Sigma}$ and $C_{n}^{W}$ for different stages of seam metamorphism are shown in Table 3 .

The general carbonation index $\left(C_{n}\right)$ is associated with $C_{n}^{\Sigma}$ and $C_{n}^{W}$ through the expression:

$$
\frac{1}{C_{n}}=\frac{1}{C_{n}^{\Sigma}}+\frac{1}{C_{n}^{W}} .
$$

Taking the $C_{n}^{-1}$ value per unit for each stage of seam metamorphism, we determined the shares of participation, respectively, and the sum of the organic matter components $\left(\Delta C_{n}^{\Sigma}\right)$ and moisture $\left(\Delta C_{n}^{W}\right)$ :

$$
\begin{aligned}
\Delta C_{n}^{\Sigma} & =\frac{1}{C_{n}^{\Sigma}} \cdot \frac{1}{C_{n}}, \\
\Delta C_{n}^{W} & =\frac{1}{C_{n}^{W}} \cdot \frac{1}{C_{n}},
\end{aligned}
$$


Table 2: Ranking the content of organic matter and moisture components in coal samples.

\begin{tabular}{|c|c|c|c|c|c|c|c|c|c|c|}
\hline \multirow{2}{*}{ Rank } & \multicolumn{10}{|c|}{ Metamorphism stages } \\
\hline & $\mathrm{I}$ & II & III & IV & $\mathrm{V}$ & VI & VII & VII & IX & $x$ \\
\hline \multicolumn{11}{|c|}{ Ranking of components by coke yield } \\
\hline 1 & $\bar{C}_{0}$ & $\bar{C}_{0}$ & $\bar{C}_{0}$ & $\bar{C}_{0}$ & $\bar{C}_{0}$ & $\bar{C}_{0}$ & $\bar{C}_{0}$ & $\bar{C}_{0}$ & $\bar{C}_{0}$ & $\bar{C}_{0}$ \\
\hline 2 & $\bar{O}_{0}$ & $\bar{O}_{0}$ & $\bar{O}_{0}$ & $\bar{O}_{0}$ & $\bar{H}_{0}$ & $\bar{H}_{0}$ & $\bar{H}_{0}$ & $\bar{H}_{0}$ & $\bar{H}_{0}$ & $\bar{H}_{0}$ \\
\hline 3 & $\bar{W}$ & $\bar{W}$ & $\bar{H}_{0}$ & $\bar{H}_{0}$ & $\bar{O}_{0}$ & $\bar{O}_{0}$ & $\bar{O}_{0}$ & $\bar{O}_{0}$ & $\bar{N}_{0}$ & $\bar{H}_{0}$ \\
\hline 4 & $\bar{H}_{0}$ & $\bar{H}_{0}$ & $\bar{W}$ & $\bar{W}$ & $\bar{N}_{0}$ & $\bar{N}_{0}$ & $\bar{N}_{0}$ & $\bar{N}_{0}$ & $\bar{W}$ & $\bar{N}_{0}$ \\
\hline 5 & $\bar{S}_{0}$ & $\bar{S}_{0}$ & $\bar{N}_{0}$ & $\bar{N}_{0}$ & $\bar{W}$ & $\bar{S}_{0}$ & $\bar{S}_{0}$ & $\bar{S}_{0}$ & $\bar{O}_{0}$ & $\bar{S}_{0}$ \\
\hline 6 & $\bar{N}_{0}$ & $\bar{N}_{0}$ & $\bar{S}_{0}$ & $\bar{S}_{0}$ & $\bar{S}_{0}$ & $\bar{W}$ & $\bar{W}$ & $\bar{W}$ & $\bar{S}_{0}$ & $\bar{N}_{0}$ \\
\hline \multicolumn{11}{|c|}{ Ranking of components in relation to carbon $\bar{C}_{0}$ content } \\
\hline 1 & $\bar{O}_{0}$ & $\bar{O}_{0}$ & $\bar{O}_{0}$ & $\bar{O}_{0}$ & $\bar{H}_{0}$ & $\bar{H}_{0}$ & $\bar{H}_{0}$ & $\bar{H}_{0}$ & $\bar{H}_{0}$ & $\bar{W}$ \\
\hline 2 & $\bar{W}$ & $\bar{W}$ & $\bar{H}_{0}$ & $\bar{H}_{0}$ & $\bar{O}_{0}$ & $\bar{O}_{0}$ & $\bar{O}_{0}$ & $\bar{O}_{0}$ & $\bar{W}$ & $\bar{H}_{0}$ \\
\hline 3 & $\bar{H}_{0}$ & $\bar{H}_{0}$ & $\bar{W}$ & $\bar{W}$ & $\bar{N}_{0}$ & $\bar{N}_{0}$ & $\bar{N}_{0}$ & $\bar{N}_{0}$ & $\bar{N}_{0}$ & $\bar{N}_{0}$ \\
\hline 4 & $\bar{S}_{0}$ & $\bar{S}_{0}$ & $\bar{N}_{0}$ & $\bar{N}_{0}$ & $\bar{W}$ & $\bar{W}$ & $\bar{S}_{0}$ & $\bar{S}_{0}$ & $\bar{O}_{0}$ & $\bar{S}_{0}$ \\
\hline 5 & $\bar{N}_{0}$ & $\bar{N}_{0}$ & $\bar{S}_{0}$ & $\bar{S}_{0}$ & $\bar{S}_{0}$ & $\bar{S}_{0}$ & $\bar{W}$ & $\bar{W}$ & $\bar{S}_{0}$ & $\bar{O}_{0}$ \\
\hline \multicolumn{11}{|c|}{ Ranking of components by the percentage of participation in carbonation } \\
\hline 1 & $\bar{O}_{0}$ & $\bar{O}_{0}$ & $\bar{O}_{0}$ & $\bar{O}_{0}$ & $\bar{H}_{0}$ & $\bar{H}_{0}$ & $\bar{H}_{0}$ & $\bar{H}_{0}$ & $\bar{H}_{0}$ & $\bar{H}_{0}$ \\
\hline 2 & $\bar{H}_{0}$ & $\bar{H}_{0}$ & $\bar{H}_{0}$ & $\bar{H}_{0}$ & $\bar{O}_{0}$ & $\bar{O}_{0}$ & $\bar{O}_{0}$ & $\bar{O}_{0}$ & $\bar{O}_{0}$ & $\bar{W}$ \\
\hline 3 & $\bar{W}$ & $\bar{W}$ & $\bar{N}_{0}$ & $\bar{N}_{0}$ & $\bar{N}_{0}$ & $\bar{N}_{0}$ & $\bar{N}_{0}$ & $\bar{N}_{0}$ & $\bar{N}_{0}$ & $\bar{N}_{0}$ \\
\hline 4 & $\bar{S}_{0}$ & $\bar{S}_{0}$ & $\bar{S}_{0}$ & $\bar{S}_{0}$ & $\bar{S}_{0}$ & $\bar{S}_{0}$ & $\bar{S}_{0}$ & $\bar{S}_{0}$ & $\bar{S}_{0}$ & $\bar{S}_{0}$ \\
\hline 5 & $\bar{N}_{0}$ & $\bar{N}_{0}$ & $\bar{W}$ & $\bar{W}$ & $\bar{W}$ & $\bar{W}$ & $\bar{W}$ & $\bar{W}$ & $\bar{W}$ & $\bar{O}_{0}$ \\
\hline
\end{tabular}

The calculated values for each stage of metamorphism are shown in Table 3. The proportions of participation of the sum of the organic matter components $\left(\Delta C_{n}^{\Sigma}\right)$ and moisture $\left(\Delta C_{n}^{W}\right)$ in carbonization change significantly with an increase in the carbon content (Fig. 2a).

For this reason, we corrected the initial values $\bar{H}_{0}, \bar{N}_{0}, \bar{S}_{0}, \bar{O}_{0}$ and $\bar{W}$ for each stage, multiplying them, respectively, by $\Delta C_{n}^{\Sigma}$ and $\Delta C_{n}^{W}$ (Table 3 ). Correction of the $\bar{H}_{0}, \bar{N}_{0}, \bar{S}_{0}, \bar{O}_{0}$ and $\bar{W}$ values on the proportion of their participation in carbonization $\left(\Delta C_{n}^{\Sigma}\right.$ and $\left.\Delta C_{n}^{W}\right)$ practically did not affect the changes in the series of ranking of components in comparison with the series of ranking in terms of coke yield (Table 2). In the early stages of metamorphism (I, II), the main components affecting carbonization were oxygen content $\left(\bar{O}_{0}\right)$ and moisture $(\bar{W})$. At the next stages, oxygen and hydrogen (III, IV), hydrogen and oxygen $(\mathrm{V} \div \mathrm{VIII})$, hydrogen and moisture (IX), moisture and hydrogen (X) sequentially occupied the leading positions. The compared ranks of ranking the organic matter components in terms of the yield of coke and the index of carbonation practically do not differ among themselves and in the arrangement of the remaining members of these rows. For example, at the final stage $(\mathrm{X})$, they are located in the same order $-\bar{W}$, 
$\bar{H}_{0}, \bar{N}_{0}, \bar{S}_{0}, \bar{O}_{0}$.

This indicates that when establishing the stages of seam metamorphism, taking into account their classical definition (ASTM D388-15, 2012), it is possible to use the value of carbon content $(\bar{K})$ in organic matter instead of the coking index $\left(\bar{C}_{0}\right)$.

An additional argument for the acceptance of the carbon content as the main fission criterion at the stage of

Table 3: Results of determination of carbonization indices for organic matter components at different stages of metamorphic transformations of seams.

\begin{tabular}{|c|c|c|c|c|c|c|c|c|c|c|}
\hline \multirow[t]{2}{*}{ Indicators } & \multicolumn{10}{|c|}{ Carbon content in organic matter, $\bar{C}_{0}, \%$} \\
\hline & 80,19 & 81,57 & 84,29 & 86,43 & 88,33 & 89,53 & 90,43 & 91,46 & 92,67 & 93,65 \\
\hline$C_{n}^{\Sigma}$ & 4,05 & 4,43 & 5,37 & 6,37 & 7,57 & 8,55 & 9,45 & 10,71 & 12,64 & 21,53 \\
\hline$C_{n}{ }^{W}$ & 10,93 & 12,67 & 32,5 & 54,36 & 76,81 & 90,43 & 102,76 & 117,26 & 71,84 & 28,21 \\
\hline$\left(C_{n}^{\Sigma^{2}}\right)^{-1}$ & 0,25 & 0,23 & 0,19 & 0,16 & 0,13 & 0,12 & 0,11 & 0,09 & 0,08 & 0,05 \\
\hline$\left(C_{n}^{W}\right)^{-1}$ & 0,09 & 0,08 & 0,03 & 0,02 & 0,013 & 0,011 & 0,01 & 0,009 & 0,014 & 0,035 \\
\hline$\left(C_{n}^{\Sigma}\right)^{-1}+$ & 0,339 & 0,31 & 0,22 & 0,18 & 0,143 & 0,131 & 0,120 & 0,099 & 0,094 & 0,085 \\
\hline$\Delta C_{n}^{\Sigma}$ & 0,730 & 0,74 & 0,86 & 0,89 & 0,910 & 0,92 & 0,92 & 0,91 & 0,85 & 0,59 \\
\hline$\Delta C_{n}^{W}$ & 0,270 & 0,26 & 0,14 & 0,11 & 0,090 & 0,08 & 0,08 & 0,09 & 0,15 & 0,41 \\
\hline $\bar{H}_{0}$ & 5,34 & 5,31 & 5,31 & 5,21 & 5,10 & 4,81 & 4,60 & 4,30 & 3,75 & 1,93 \\
\hline $\bar{H}_{0} \cdot \Delta C_{n}^{\Sigma}$ & 3,90 & 3,93 & 4,56 & 4,64 & 4,64 & 4,81 & 4,23 & 3,91 & 3,19 & 1,14 \\
\hline $\bar{N}_{0}$ & 1,43 & 1,44 & 1,44 & 1,46 & 1,52 & 1,51 & 1,51 & 1,38 & 1,32 & 1,05 \\
\hline $\bar{N}_{0} \cdot \Delta C_{n}^{\Sigma}$ & 1,04 & 1,07 & 1,24 & 1,30 & 1,38 & 1,39 & 1,39 & 1,26 & 1,12 & 0,62 \\
\hline $\bar{S}_{0}$ & 2,28 & 1,83 & 1,42 & 1,24 & 1,10 & 1,04 & 1,06 & 1,03 & 1,00 & 0,74 \\
\hline $\bar{S}_{0} \cdot \Delta C_{n}^{\Sigma}$ & 1,66 & 1,35 & 1,22 & 1,10 & 1,00 & 0,96 & 0,98 & 0,94 & 0,85 & 0,44 \\
\hline $\bar{O}_{0}$ & 10,76 & 9,85 & 7,54 & 5,66 & 3,95 & 3,11 & 2,40 & 1,83 & 1,26 & 0,63 \\
\hline $\bar{O}_{0} \cdot \Delta C_{n}^{\Sigma}$ & 7,96 & 7,30 & 6,47 & 5,04 & 3,60 & 2,86 & 2,21 & 1,67 & 1,07 & 0,38 \\
\hline $\bar{W}$ & 7,34 & 6,44 & 2,59 & 1,59 & 1,15 & 0,99 & 0,88 & 0,78 & 1,29 & 3,32 \\
\hline $\bar{W} \cdot \Delta C_{n}^{W}$ & 1,98 & 1,67 & 0,67 & 0,41 & 0,30 & 0,26 & 0,23 & 0,20 & 0,34 & 0,86 \\
\hline$C_{n}^{H}$ & 20,30 & 20,77 & 18,44 & 18,63 & 19,04 & 20,21 & 21,38 & 23,39 & 29,05 & 82,15 \\
\hline$C_{n}^{N}$ & 75,65 & 76,23 & 67,98 & 66,48 & 64,01 & 64,41 & 65,06 & 72,59 & 82,74 & 151,05 \\
\hline$C_{n}^{S}$ & 47,45 & 60,42 & 69,1 & 78,57 & 88,33 & 93,26 & 92,28 & 97,30 & 109,02 & 212,84 \\
\hline$C_{n}^{O}$ & 10,07 & 11,2 & 13,01 & 17,15 & 24,6 & 31,30 & 40,92 & 54,77 & 86,61 & 246,44 \\
\hline$C_{n}^{W}$ & 41,98 & 48,84 & 125,81 & 210,8 & 294,43 & 344,35 & 393,17 & 457,3 & 272,56 & 108,9 \\
\hline$\left(C_{n}^{H}\right)^{-1}$ & 0,049 & 0,048 & 0,054 & 0,054 & 0,053 & 0,049 & 0,047 & 0,043 & 0,034 & 0,012 \\
\hline$\left(C_{n}^{N}\right)^{-1}$ & 0,013 & 0,013 & 0,015 & 0,015 & 0,016 & 0,016 & 0,015 & 0,014 & 0,012 & 0,007 \\
\hline$\left(C_{n}^{S}\right)^{-1}$ & 0,021 & 0,017 & 0,014 & 0,013 & 0,011 & 0,011 & 0,011 & 0,010 & 0,009 & 0,005 \\
\hline$\left(C_{n}^{O}\right)^{-1}$ & 0,098 & 0,089 & 0,077 & 0,058 & 0,041 & 0,032 & 0,024 & 0,018 & 0,012 & 0,004 \\
\hline$\left(C_{n}^{W}\right)^{-1}$ & 0,024 & 0,020 & 0,008 & 0,005 & 0,003 & 0,003 & 0,003 & 0,002 & 0,004 & 0,009 \\
\hline$\Sigma\left(C_{n}^{i}\right)^{-1}$ & 0.206 & 0,187 & 0,168 & 0,145 & 0,124 & 0,111 & 0,10 & 0,087 & 0,071 & 0,037 \\
\hline$\Delta C_{n}^{H}$ & 0,237 & 0,257 & 0,32 & 0,37 & 0,43 & 0,44 & 0,47 & 0,49 & 0,48 & 0,32 \\
\hline$\Delta C_{n}^{N}$ & 0,063 & 0,070 & 0,09 & 0,10 & 0,13 & 0,14 & 0,15 & 0,160 & 0,17 & 0,19 \\
\hline$\Delta C_{n}^{S}$ & 0,101 & 0,09 & 0,08 & 0,09 & 0,09 & 0,10 & 0,110 & 0,11 & 0,13 & 0,14 \\
\hline$\Delta C_{n}^{O}$ & 0,478 & 0,47 & 0,46 & 0,40 & 0,33 & 0,29 & 0,24 & 0,21 & 0,17 & 0,11 \\
\hline$\Delta C_{n}^{W}$ & 0,121 & 0,11 & 0,05 & 0,03 & 0,02 & 0,03 & 0,03 & 0,02 & 0,05 & 0,24 \\
\hline
\end{tabular}


seam metamorphism is the individual graphs of the mutual changes in the components of organic matter (Fig. 3). The intersection points of the curves characterizing the individual change in the organic matter components indicate not only a change in the chemical composition but also a change in the physical and mechanical properties. With this assumption, the initial stage of seams metamorphism (I) corresponds to a carbon content of less than $83 \%$. The upper limit of $83 \%$ is determined by points 6 and 7 of curve intersection 4, 5, and 2,3 . Curves 4 and 5 , respectively, characterize the change in the content of nitrogen $\left(\bar{N}_{0}\right)$ and sulfur $\left(\bar{S}_{0}\right)$, and curves 2 and 3 the content of hydrogen $\left(\bar{H}_{0}\right)$ and oxygen $\left(\bar{O}_{0}\right)$ and moisture $(\bar{W})$. Similarly, the upper limit $\left(\bar{N}_{0}=87 \%\right)$ of stage II was determined by points 8 and 9 . They correspond to the intersection of curves 3,4 and 1,2 , which determine, respectively, the moisture content $(\bar{W})$ and nitrogen $\left(\bar{N}_{0}\right)$ and sulfur $\left(\bar{S}_{0}\right)$, and curves 2 and 3 - oxygen $\left(\bar{O}_{0}\right)$ and hydrogen $\left(\bar{H}_{0}\right)$ content.

The upper limit of stage III $\left(\bar{C}_{0}=89 \%\right)$ is determined by point 10 of curve intersection 3 and 5 . The points of intersection 11 and 12 correspond to the end of stage IV (curves 3, 5, and 1, 4). Point 13 corresponds to the intersection of curves 3, 4 (stage V). The intersection of curves 1 and 5 at point 14 defines stage VI. Stages VII and VIII differ by tenths of a percentage of carbon, and the limits of stages IX - X cannot be determined from the available data (Table 4), since in this case, the carbon content is less than $93.6 \%$. Stages of seam metamorphism at $\bar{C}_{0}>93.6 \%$ can differ significantly in properties due to the unpredictability of the ratio between the organic matter components. At these stages, even a slight difference between the components can be the reason for the emergence of new properties of the coal seams. As the influence of the processes of metamorphism increases, the boundaries of the stages, determined by the percentage of carbon, narrow.

According to the method described above (equations 2-6,), the corrected shares of individual participation in the carbonization of hydrogen $\left(\Delta C_{n}{ }^{H}\right)$, oxygen $\left(\Delta C_{n}{ }^{O}\right)$, nitrogen $\left(\Delta C_{n}^{N}\right)$, sulfur $\left(\Delta C_{n}^{S}\right)$, and moisture $\left(\Delta C_{n}{ }^{W}\right)$ were calculated.

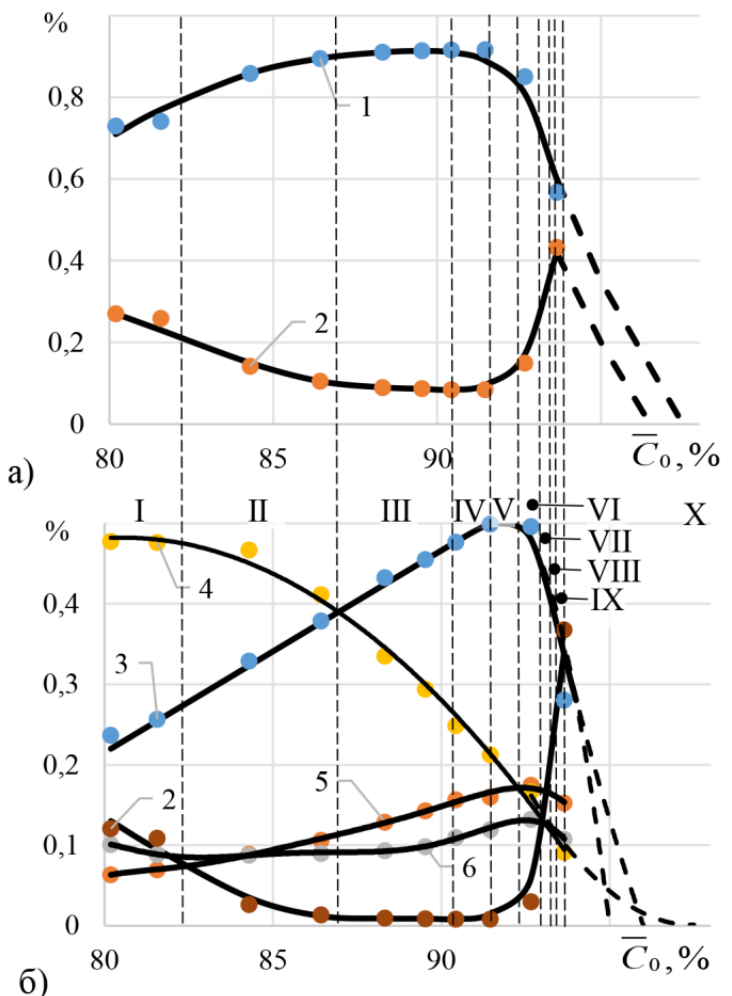

Fig. 2: The dependence of the change in the share of participation in the carbonization of layers of organic matter components on the average carbon content $\left(\bar{C}_{0}\right)$.

1,2 - curves of changes in the share of participation in carbonization, respectively, the sum of components $\left(C_{n}{ }^{\Sigma}\right)$ of organic matter $\left(\bar{H}_{0}, \bar{N}_{0}, \bar{S}_{0}, \bar{O}_{0}\right)$ and moisture $\left.\Delta C_{n}{ }^{W}\right) ; 3,4,5,6$ - curves of changes in the proportion of participation in carbonization of hydrogen $\left(\Delta C_{n}{ }^{H}\right)$, oxygen $\left(\Delta C_{n}{ }^{O}\right)$, nitrogen $\left(\Delta C_{n}{ }^{N}\right)$ and sulfur $\left(\Delta C_{n}{ }^{S}\right)$, respectively; I, II, III, IV, V, VI, VII, VIII, IX, X - stages of seam metamorphism. 


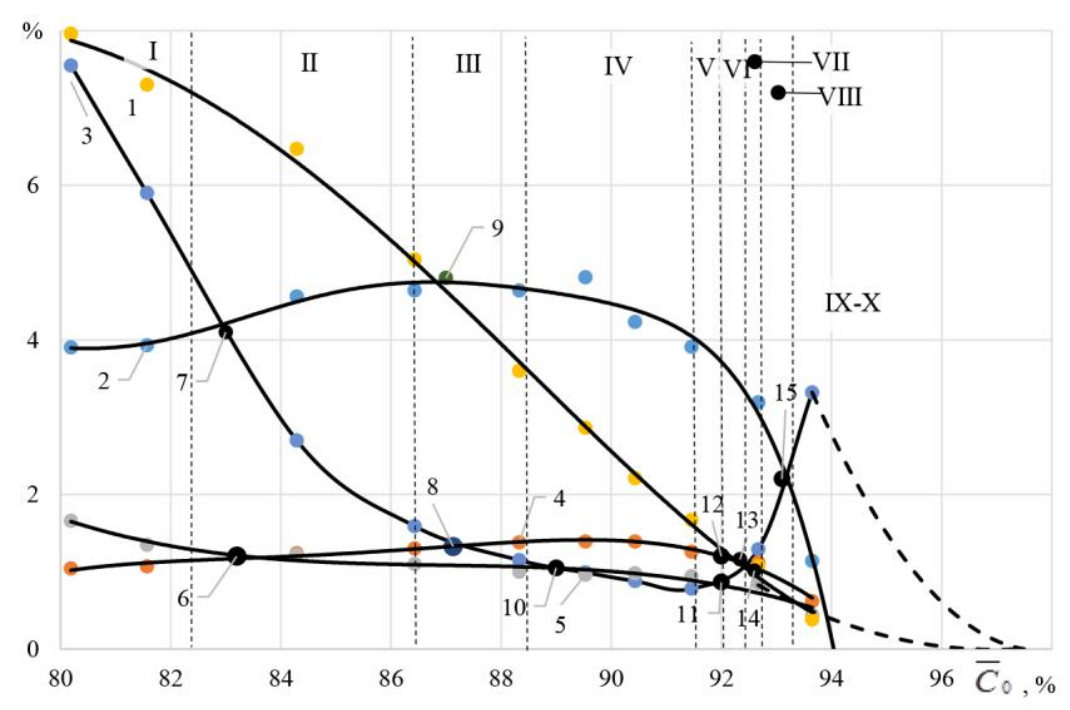

Fig. 3: Dependence of the average values of the content of components in organic matter on carbon.

$1,2,3,4,5,-$ curves of the average content in organic matter, respectively, of oxygen $\left(\bar{O}_{0}\right)$, hydrogen $\left(\bar{H}_{0}\right)$, moisture $(\bar{W})$, nitrogen $\left(\bar{N}_{0}\right)$ and sulfur $\left(\bar{S}_{0}\right) ; 6,7,8,9,10,11,12,13,14$ - characteristic points of curve intersections defining the boundaries of the stages of layer metamorphism;

I, II, III, IV, V, VI, VII, VIII, IX, X - stages of seam metamorphism, determined by the characteristic points of curve intersection.

Table 4: Change of elemental content of carbon in organic matter at different stages of reservoir transformation.

\begin{tabular}{|c|c|c|c|c|c|c|c|c|c|c|}
\hline \multirow[t]{2}{*}{ Stage determination criterion } & \multicolumn{10}{|c|}{ Stages of seam metamorphism and carbon content, $\%$} \\
\hline & I & II & III & IV & $\mathrm{V}$ & VI & VII & VII & IX & $\mathrm{X}$ \\
\hline Coke yield, $\bar{K}, \%$ & 80,19 & 81,57 & 84,29 & 86,43 & 88,33 & 89,53 & 90,43 & 91,46 & 92,67 & 93,5 \\
\hline $\begin{array}{l}\text { Carbonation according to the individual content } \\
\text { of moisture and organic matter components }\end{array}$ & $\begin{array}{l}80,0- \\
83,0\end{array}$ & $\begin{array}{l}83,0- \\
87,0\end{array}$ & $\begin{array}{l}87,0- \\
89,0\end{array}$ & $\begin{array}{l}89,0- \\
92,0\end{array}$ & $\begin{array}{l}92,0- \\
92,7\end{array}$ & $\begin{array}{l}92,7- \\
93,0\end{array}$ & $\begin{array}{l}93,0- \\
93,2\end{array}$ & $\begin{array}{l}93,2- \\
93,6\end{array}$ & over 9 & \\
\hline $\begin{array}{l}\text { Individual share of participation of organic } \\
\text { matter components in carbonization }\end{array}$ & $\begin{array}{l}80,0- \\
83,4\end{array}$ & $\begin{array}{l}83,4- \\
86,0\end{array}$ & $\begin{array}{l}86,0- \\
90,4\end{array}$ & $\begin{array}{l}90,4- \\
91,8\end{array}$ & $\begin{array}{l}91,8- \\
92,5\end{array}$ & $\begin{array}{l}92,5- \\
93,2\end{array}$ & $\begin{array}{l}93,2- \\
93,4\end{array}$ & $\begin{array}{l}93,4- \\
93,6\end{array}$ & over 9 & \\
\hline
\end{tabular}

Their values (Table 3) changed significantly in the process of metamorphic transformations of seams. There are also differences in the ranks of ranking according to the proportion of the participation of components in carbonization in comparison with the ranks ranked according to the elemental organic matter composition (Table 2). The presence of moisture plays a significant role in the early stages (I, II) of reservoir transformation. At the next stages (III-IX), the proportion of its influence on carbonation is minimal in comparison with other components. At the last stage (X), the role of moisture increases again, and it returns to one of the leading places in the ranking. After reaching a carbon content of more than $93.6 \%$, a sharp decrease in the share of participation in carbonization (Fig. 2b) of all other components $\left(\bar{H}_{0}, \bar{N}_{0}, \bar{S}_{0}, \bar{O}_{0}\right.$ and $\left.\bar{W}\right)$ is predicted. In this case, their total share in organic matter will not exceed $6.4 \%$, which undoubtedly affects the properties of coal seams during mining.
The established stages of seam transformation in terms of the individual share of the components in carbonization practically do not differ from the limits of the stages established by the elemental composition of organic matter (Fig. $2 \mathrm{~b}$, Table 4). It should also be noted that the average carbon content at the stages of seam metamorphism, determined by the coke yield, in most cases does not coincide with the ranges of variation established by the individual content of the components or their share in carbonization (Table 4). The inconsistency of the limits of the stages of seam metamorphism makes it unacceptable to use the coke yield as the main criterion for assessing the conversion of coal and even more so the manifestation of hazardous properties of seams.

\section{CONCLUSION}

The conducted research and the results obtained allowed us to draw conclusions that are important for improving the regulatory framework for safe mining of coal seams: 
- The indicators of the yield of volatile substances during the thermal decomposition of coals currently used in the regulatory framework are not directly related to the stages of seam transformation in natural conditions. Thermal decomposition under artificial conditions is the next stage in the transformation of coals at a higher temperature;

- The main indicators of the regulatory framework are determined for the dry ash-free state of organic matter (daf), which does not correspond to its state in coal seams during mining;

- The use of indicators of the volatile substances released during the thermal decomposition of coals to characterize the hazardous properties of coal seams is borrowed from industrial classifications without proper justification. They only conditionally characterize the brands of coal for their industrial use by genetic and basic energy and technological characteristics;

- The stages of metamorphism, according to the GOST definition, characterize the degree of change in the chemical composition, structure, and properties of coal, achieved during coal formation and determining its position in the genetic series: brown coal - hard coal - anthracite. None of the indicators of the regulatory framework correspond to this definition of the degree of metamorphism;

- One of the main signs of an increase in the degree of metamorphism is an increase in the carbon content in organic matter and a decrease in the sum of the remaining components;

- According to technical and elemental analysis, the presence of seam moisture is not considered in the composition of organic matter, which unreasonably excludes its influence on the physicochemical state of the mines;

- The main components of organic matter are carbon, hydrogen, nitrogen, sulfur, oxygen, and moisture. Their total content at all stages of formation transformation is close to $100 \%$;

- In the process of metamorphic transformations of coal seams, there is an ambiguous change in the ratio between the main components of the elemental composition of organic matter;

- The hazardous properties of coal seams are determined not only by the elemental composition of organic matter but also by the share of each component in carbonization.

\section{REFERENCES}

Ahamed, M. A. A., Perera, M. S. A., Matthai, S. K., Ranjith, P. G. and Dong-yin, L. 2019. Coal composition and structural variation with rank and its influence on the coal-moisture interactions under coal seam temperature conditions: A review article. J. Pet. Sci. Eng., 180: 901-917.

Antoshchenko, M., Filatieva, E., Yefimtsev, V. and Tarasov, V. 2020. Peculiarities of using classification indicators of the coal metamorphism degree for predicting the hazardous coal seams properties. E3S Web of Conf., 01014: 1-10.

ASTM D388-15. 2012. Standard Classification of Coals by Rank, ASTM International, West Conshohocken, PA

GOST 25543-2013. 2014. Brown Coals, Hards Coals, and Anthracites. Classification According to Genetic and Technological Parameters: State Standard of the USSR. Izd-vo Standartov, Moscow.

GOST 6382-2007. 2008. Solid Mineral fuel: Methods for Determination of Volatile Matter Yield. Izd-vo Standartov, Moscow.

Klymenko, V., Gutsul, V., Bondarenko, V., Martynenko, V. and Stets, P. 2019. Modeling of the kinetics of the gas hydrates formation on the basis of a stochastic approach. Solid State Phen. Trans. Tech. Publ. Ltd., 109-98:291

Qi, Y. (ed.) 2020. Geology of Fossil Fuels-Coal. Proceedings of the 30th International Geological Congress, 4-14 August 2020, Beijing, China. CRC Press, London, p. 168.

Sen, S. and Banerjee, S. 2015. Identifying Relationship Amongst Vitrinite/ Inertinite Ratio (V/I), Cleat Parameters, Vitrinite Reflectance, O/C Ratio and Permeability of Coal Seams and V/I Ratio as Exploration Tool: Study from Raniganj Coal Bed Methane Block, Essar Oil Limited, India. In Mukherjee, S. (ed.), Petroleum Geosciences: Indian Contexts. Springer, Cham, pp. 205-217.

Thomas, L. 2020. Coal Geology. John Wiley \& Sons, New York. 